\title{
O ENSINO DE HUMANIDADES NO CONTEXTO BRASILEIRO
}

\author{
Ivan de Freitas Vasconcelos Junior ${ }^{1}$; Eliane Aparecida Galvão dos Santos ${ }^{2}$
}

\section{RESUMO}

Este trabalho aborda questões relacionadas à relevância das humanidades na formação de sujeitos e na estimulação do pensamento crítico. O objetivo geral é compreender o ensino de humanidades no contexto brasileiro. A pesquisa é de abordagem qualitativa do tipo bibliográfica. Realizou-se uma pesquisa em acervos físicos e na internet, considerando as contribuições de autores como Rouanet (1998), Nussbaum (2015), Kemp (2018), dentre outros. O estudo aponta para a perda de espaço das disciplinas de humanidades nos componentes curriculares das instituições de ensino brasileiras. Também foi verificado que o ensino de humanidades continua sendo fundamental para a formação cidadã e que se necessita debater o tema, principalmente no que diz respeito às razões que justifiquem a importância da educação humanística na formação dos estudantes.

Palavras-chave: Bulding; Educação humanística; Paideia.

Eixo Temático: Educação, Cultura e Comunicação.

\section{INTRODUÇÃO}

As humanidades é uma das áreas do saber mais antigas e remontam à época da Grécia Antiga, cujo sistema educacional tinha o foco de desenvolver algumas qualidades no indivíduo, como a clareza do pensamento, o encadeamento de ideias e a articulação da fala e da expressão.

Ao longo da trajetória educativa, o ensino humanista por vezes esteve atrelado ao desenvolvimento de capacidades voltadas à vida pública, pois a expressão e a articulação da linguagem (oratória) são atributos imprescindíveis para o homem público. Com o tempo, as humanidades passaram a significar muito mais do que simplesmente preparar o cidadão para a vida pública, pois elas possuem

\footnotetext{
1 Mestrando do Programa de Pós-Graduação em Ensino de Humanidades e Linguagens da Universidade Franciscana (Santa Maria/RS) - ivan_junior_neo@hotmail.com.

2 Orientadora. Professora do Programa de Pós-Graduação em Ensino de Humanidades e Linguagens da Universidade Franciscana (Santa Maria/RS) - elianea@ufn.edu.br.
} 
uma característica intrínseca de formar o sujeito para a autonomia, possibilitando ao indivíduo o desenvolvimento de ferramentas que vão fomentar seu caráter.

Hoje é evidente a relevância das humanidades na formação de sujeitos, na estimulação do pensamento crítico, no desenvolvimento da capacidade de empatia e no aprimoramento da capacidade ética. Embora haja movimentos para esvaziar a educação humanística ou diminuir a influência do ensino das humanidades nos processos formativos, é cada vez mais urgente a defesa da área humanística, uma vez que ela tem um grande potencial para a abertura ao questionamento, à interrogação da realidade e à problematização das questões ético-morais na sociedade.

Nesse contexto, o objetivo geral deste artigo é compreender o ensino de humanidades no contexto brasileiro. Para isso, tem-se como objetivos específicos: entender o ensino das humanidades em uma perspectiva histórica e caracterizar a educação humanística.

\section{METODOLOGIA}

A pesquisa é de abordagem qualitativa do tipo bibliográfica, com base nas informações coletas em algumas publicações científicas. A utilização desse tipo de pesquisa auxilia na construção e na definição do quadro conceitual que envolve o objeto de estudo, conforme aponta Gil (2008).

Quanto às características, a pesquisa é do tipo descritiva, já que há o intuito de descrever o ensino das humanidades no Brasil, estabelecendo relações com o panorama histórico e traçando perspectivas futuras. Assim, tentou-se expandir os conhecimentos por meio de coleta do máximo de informações possíveis para compor o corpus de análise (GERHARDT; SILVEIRA, 2009).

A revisão da literatura partiu da leitura de publicações especializadas, livros e trabalhos científicos relacionados ao tema. Para isso, foram realizadas buscas na plataforma do Google Acadêmico utilizando as seguintes palavras-chaves: "ensino", "humanidades" e "paideia". Após a realização do levantamento, foi realizada a seleção da bibliografia, coleta e crítica dos dados, por meio da utilização de critérios de inclusão e exclusão. 
Como critérios de inclusão, foram aceitos textos em português, inglês ou espanhol, publicados no período de 1990 a 2021, que remetessem à evolução do ensino de humanidades no Brasil. Como critérios de exclusão e coerência, foram retirados do corpus de análise os estudos com método de pesquisa de difícil definição ou não explícito, bem como, textos desprovidos de base científica.

Utilizou-se as obras de Aranha (1996), Rouanet (1998), Nussbaum (2015) e Kemp (2018) para subsidiar o debate em torno da temática, dessa forma, teve-se a preocupação de coletar as informações tanto em periódicos recentes, quanto em obras de autores clássicos que discutem o ensino de humanidades.

\section{RESULTADOS E DISCUSSÕES}

O estudo das humanidades perpassa necessariamente sobre a formação do homem ou ainda sobre a compreensão do ser humano. A origem das humanidades remonta à Idade Antiga, particularmente na antiguidade grecoromana, cujo entendimento de formação do homem (ou paideia) era baseado na totalidade da existência humana, inclusive no exercício da participação política.

O âmago da educação grega era modelar os indivíduos pela norma da comunidade. Para os gregos, a ideia de "homem" (no sentido de cidadão) não se constituía em um esquema vazio e desvinculado do tempo e do espaço. A desconsideração do caráter histórico e a exclusão das dimensões de existência humana não eram aspectos presentes nas concepções gregas (KEMP, 2018).

Por ocasião do período renascentista, as humanidades passaram a se particularizar em um conjunto de disciplinas que compunham um currículo denominado como studia humanitatis, que abrangia as áreas da retórica, gramática, poesia, história e ética (BURKE, 2003). Estas disciplinas eram estudadas com base nos manuscritos greco-romanos. $O$ ensino de humanidades tinha a pretensão de integrar os saberes específicos com as capacidades políticas dos sujeitos, assim, os discentes deveriam desenvolver primordialmente a arte de ler os textos clássicos e saber se expressar em público.

$\mathrm{Na}$ Modernidade, o conceito de formação passou a focar na autonomia do sujeito e no indivíduo como o centro do estudo. Com o iluminismo alemão, o termo 
bildung passou a ser um conceito que balizava o processo formativo do cidadão. $\mathrm{Na}$ língua alemã, o conceito de bildung é carregado de significados associados à ideia de imagem (bild) e forma, nesse panorama, o bildung traz consigo um processo educativo para dar forma ao ser humano, baseado em uma imagem ideal que dele se estabelece.

A conceituação contemporânea do termo formação traz consigo outras características para além da paideia ou do bildung. Nos dias atuais, atribui-se um papel diferente à educação em virtude das novas demandas de um mundo globalizado e capitalista. Nessa lógica, o indivíduo esforça-se para seu autoaperfeiçoamento e para a especialização no mercado de trabalho, com vistas à eficiência e aos resultados. "Não é mais o homem, portanto, que se realiza por meio de seu trabalho, e sim a sociedade de trabalho que se efetua por meio da economização abrangente do homem" (KEMP, 2018, p. 22).

Nesse panorama, o ideal de formação está voltado para a eficiência técnica, distanciando-se da noção de bildung e de paidea. Atualmente há uma busca dos indivíduos pela qualificação, não aquela voltada para a formação de si (desenvolvendo habilidades do ser humano crítico-reflexivo, intra e interpessoal), mas aquela voltada a atender as demandas profissionais (desenvolvendo habilidades instrumentais para atender o mercado de trabalho).

Os recursos investidos no ensino são fortemente influenciados por uma pressão por racionalização econômica, nesse contexto, há uma crescente desvalorização do ensino de humanidades, visto que a educação humanista tem custos financeiros elevados, de acordo com Nussbaum (2015). Ao trazer para o debate as questões relacionadas ao ensino de humanidades, faz-se necessário esclarecer que este trabalho parte do entendimento de humanidades como:

Disciplinas que contribuam para a formação (bildung) do homem independentemente de qualquer finalidade utilitária imediata, isto é, que não tenham necessariamente como objetivo transmitir um saber científico ou uma competência prática, mas estruturar uma personalidade, segundo uma certa paidea, vale dizer, um ideal civilizatório e uma normativa inscrita na tradição, ou simplesmente proporcionar um prazer lúdico. (DIAS, 1991, p. 10) 
O ensino das humanidades tem origens nas concepções de formação da paideia grega e do bildung alemão. O legado dessas concepções de formação humanística atravessou gerações e continua importante para a civilização, por trazer uma compreensão orgânica do homem, da natureza e da vida.

O ensino de humanidades constitui-se em saberes baseados na memória histórica do homem e na relação entre teoria e prática, fundamentais no momento presente e para a construção do futuro (SILVA, 2010). As humanidades estão intimamente associadas com a formação da personalidade e a elaboração do sujeito autônomo-crítico.

Em um mundo onde o indivíduo se esforça para alcançar o sucesso no mercado de trabalho ou, ainda, para sobreviver ou se manter nesse mercado, faz-se necessário repensar o ensino das humanidades, pois a formação do cidadão passa necessariamente por uma educação humanística, harmônica, formadora da personalidade humana e capaz de gerar a reflexão sobre si e sobre o mundo.

\subsection{O ensino das humanidades no Brasil}

As origens do ensino das humanidades no Brasil remetem ao período colonial. Naquela época, a educação era destinada aos filhos de alguns colonos e aos índios aldeados. Até meados do século XVIII, o ensino de humanidades baseava-se na metodologia da educação jesuítica que, por sua vez, focava nos preceitos da educação liberal da Idade Média, por meio do método do trivium $^{3} \mathrm{e}$ do quadrivium ${ }^{4}$. No entanto, o que era ensinado no Brasil Colônia era uma versão simplificada do método medieval e se baseava nas disciplinas relacionadas ao trivium, por consequência, tal simplificação resultou em uma formação brasileira bastante estilizada e literária (WEHLING et al, 1999).

A pedagogia jesuítica caracterizava-se por seu alinhamento às determinações emanadas do Concílio de Trento da Igreja Católica, cujos propósitos contrarreformistas iam de encontro ao modelo de ensino disseminado nos demais países da Europa, inspirados pelo racionalismo e pela ciência moderna. Com a

\footnotetext{
3 O trivium visava desenvolver a expressão da linguagem e abarcava o estudo da lógica, da gramática e da retórica.

${ }^{4} \mathrm{O}$ quadrivium abarcava o estudo da geometria, aritmética, música e astronomia.
} 
disseminação do lluminismo na Europa, acirrou-se a incompatibilidade entre o modelo educacional pregado pela filosofia iluminista e o modelo retrógrado de ensino português, que remetia ao período medieval. Nesse escopo, o Estado Português teve que iniciar uma reforma educacional comandada por Sebastião José de Carvalho e Melo, o Marquês de Pombal.

Essa reforma educacional ficou conhecida como reforma pombalina e impactou as colônias portuguesas. No Brasil, foi realizada a implantação de um ensino público oficial, com a retirada do monopólio educacional do domínio jesuíta e a inserção de professores régios, ou seja, por professores nomeados pelo governo em substituição aos professores jesuítas.

A reforma pombalina reformulou o curso de humanidades oferecido pelos missionários para uma sistemática baseada em aulas dispersas e fragmentadas. De acordo com Aranha (1996) foram criadas na colônia: 3 (três) aulas de filosofia, 3 (três) de grego, 6 (seis) de retórica, 15 (quinze) de gramática e 16 (dezessete) de ler e escrever. Nesse mapeamento das aulas régias, calcula-se um total de 48 (quarenta e quatro) aulas, muitas delas realizadas em escolas religiosas ou em seminários. Percebe-se, portanto, que o sistema pombalino não impediu a oferta de aulas nos colégios ligados às ordens religiosas, criadas pelos antigos missionários.

No período republicano, houve uma nova alteração na configuração do ensino de humanidades no Brasil. Ao se relembrar a Reforma de 1890 promovida pelo Ministro Benjamin Constant, verifica-se uma substituição de uma base tradicional humanista do ensino secundário para outra de cunho mais científico, em virtude do alinhamento do governo com as ideias positivistas de Augusto Comte.

Essa mudança está alinhada ao que Chervel e Compère (1999) mencionou sobre a "inevitável especialização", devido à mudança de paradigma para um ensino progressivamente mais fragmentado ou menos universalista. Nessa sistemática, 0 ensino de humanidades passou a se apoiar na utilização de textos para a memorização dos alunos e na centralidade na explicação do professor.

Nessa trajetória histórica do ensino de humanidades no Brasil, um outro ponto merece destaque e ocorre durante o regime militar no Brasil. Nesse período, algumas alterações foram efetuadas na grade curricular das escolas brasileiras 
como, por exemplo, a retirada da filosofia e do latim dos currículos, bem como, a reconfiguração das aulas da língua portuguesa (que passou a se denominar comunicação e expressão e ter uma concepção instrumental da linguagem).

Essas modificações trouxeram um receio em relação à impossibilidade de estimular o pensamento crítico dos alunos, uma vez que os componentes curriculares que foram alterados estavam intimamente relacionados à formação do pensamento crítico. Nesse sentido, ao analisar esse período, Rouanet (1998, p. 307) demonstrou seu incômodo com o fim dessas disciplinas humanísticas, já que, em sua visão, "com o fim das humanidades acabou também, em grande parte, o pensamento crítico".

No atual contexto, marcado pela intensificação do consumismo, o ideal de formação humana acaba se reduzindo à preparação técnica e instrumental para se enquadrar nas exigências do mercado consumidor, nesse bojo, a escola é tratada como uma extensão desse mercado e busca adequar o sujeito ao mundo globalizado capitalista.

Nessa perspectiva, Nussbaum (2015) afirma que a educação voltada para o crescimento econômico sempre se mostra desrespeitosa com as humanidades, uma vez que, à primeira vista, as humanidades não geram lucro e não trazem o progresso econômico de uma nação. Esse pode ser um dos motivos pelos quais os programas relacionados ao ensino de humanidades estão sofrendo cortes de recursos, na visão da autora.

Nesse ponto é interessante mencionar que, em 2017, foi sancionada no Brasil a Lei 13.415, que alterou a Lei de Diretrizes e Bases da Educação Nacional e estabeleceu mudanças na estrutura do ensino médio, por meio da delimitação de uma nova organização curricular para contemplar o que está previsto na Base Nacional Comum Curricular (BNCC) e, simultaneamente, possibilitar a escolha dos itinerários formativos pelos estudantes.

Um dos receios dessa lei é que ela pode contribuir para um desprestígio cada vez maior das humanidades, uma vez que os estudantes podem reduzir as disciplinas das humanidades de seu processo formal de ensino. Desse modo, pode 
haver um privilégio das disciplinas ditas científicas em detrimentos das disciplinas humanísticas.

A crítica que se pode fazer ao tema é que, ao estimular as disciplinas científicas, prioriza-se um estudo de instrumentalização técnica voltado ao mercado de trabalho e aos sistemas de produção, a despeito de um ensino crítico-reflexivo voltado à formação de um sujeito cognoscente. Segundo Kemp (2018, p. 85), "desprestigiar as humanidades do processo formativo escolar não é apenas excluir um conjunto de disciplinas em favor de outro, [...] é uma estratégia de esvaziamento do sentido crítico da formação".

$\mathrm{Na}$ proporção em que se reduz investimentos em disciplinas humanísticas, reduz-se também as qualidades fundamentais para o ambiente democrático, nesse panorama, faz-se necessário reavaliar o rumo tomado, refletir para onde se quer chegar enquanto sociedade e reelaborar qual a educação humanística que se deseja para as futuras gerações.

\subsection{A educação humanística}

Há um entendimento na sociedade de que a missão precípua da escola é formar sujeitos e prepará-los para a convivência democrática em sociedade. Ao se ter esse tipo de entendimento sobre o papel do ensino na vida dos jovens, outros aspectos devem ser levados em consideração como, por exemplo, a preocupação de não reduzir a educação ao aspecto utilitário e instrumental das práticas pedagógicas.

A escola não pode ser meramente instrumentalizadora, muito pelo contrário, ela deve cultivar a capacidade de reflexão e estimular o pensamento crítico, contribuindo para a manutenção de uma democracia robusta, conforme apontado por Nussbaum (2015). Essa autora defende o paradigma do desenvolvimento humano e se manifesta contrária ao paradigma do desenvolvimento econômico.

Ela também faz um alerta para que o desenvolvimento humano e o desenvolvimento econômico não sejam mutuamente excludentes, pois ambos podem coexistir e contribuir para o tipo de educação desejado para as futuras gerações. A autora entende que não há a necessidade de se escolher entre um 
modelo de ensino que promova a rentabilidade e um modelo de ensino que promova o civismo, pois ambos os modelos não se excluem e nem se anulam.

A autora ainda rebate as visões de educação como ferramenta para o crescimento econômico de uma nação e argumenta que o desenvolvimento não implica necessariamente em uma melhoria na qualidade de vida da população. Da mesma forma, ela não se furta de argumentar em favor do ensino das humanidades e propõe um modelo de educação voltado ao desenvolvimento humano, mostrando que as humanidades não são contrárias ao desenvolvimento econômico.

O paradigma do desenvolvimento humano defende a dignidade humana e que ela seja respeitada nas leis, nas instituições e nas diversas instâncias da sociedade. Diferentemente do modelo de desenvolvimento econômico, o modelo de desenvolvimento humano se compromete com a democracia, já que o "ingrediente essencial de toda vida dotada de dignidade humana é ter voz e voto na eleição das políticas que governarão a própria vida". (KEMP, 2018, p. 87).

Com base nos apontamentos de Nussbaum, Kemp (2018) elenca os princípios de uma educação humanista que precisam ser ensinados para fomentar a democracia, em uma perspectiva humana e sensível. São eles: a atitude para refletir sobre questões políticas que afetem o país; a atitude para reconhecer os cidadãos como pessoas com plenos direitos; a atitude para se interessar pela vida dos outros e entender os desdobramentos de cada política para as experiências dos demais cidadãos; a atitude para emitir juízo crítico sobre os dirigentes políticos; a atitude para pensar no bem comum da nação em sua totalidade e não como um grupo reduzido a vínculos locais; e a atitude para projetar a própria nação como parte da ordem mundial em que questões requerem uma deliberação transnacional para sua solução.

Ademais, Nussbaum (2015) enfatiza que as humanidades são importantes em todas as instâncias do conhecimento, desde a educação básica até a universidade. No entanto, ela esclarece que não tem pretensão de afirmar que as ciências exatas e as demais ciências sociais não sejam essenciais para a educação dos cidadãos, pois não está sendo proposto que essas disciplinas fiquem para trás no cronograma curricular das instituições de ensino. 
Uma educação humanística pensada para o futuro de uma sociedade democrática necessita, portanto, desenvolver algumas capacidades no campo das humanidades como, por exemplo, a capacidade de estimular a criticidade de pensamento, a capacidade de transcender questões nacionais e enfrentar problemas internacionais na qualidade de "cidadãos do mundo", além da capacidade de imaginar as dificuldades do próximo com compaixão (NUSSBAUM, 2015).

$O$ ensino das humanidades exige o reconhecimento e a prática daquilo que Ihe torna humanos, desse modo, é fundamental que cada sujeito aceite seu pertencimento a uma totalidade, que transcende o grupo ou a região a qual pertence e que compreenda que ele é um cidadão do mundo.

\section{CONCLUSÃO}

Vive-se um tempo de inovações tecnológicas que se refletem nos campos pessoais, educacionais e profissionais, nesse panorama, a educação pauta-se na racionalidade técnica visando atender a lógica do mercado. Visualiza-se, com isso, um risco de redução dos investimentos nas disciplinas humanísticas, que pode prejudicar a possibilidade de humanização das futuras gerações.

A despeito da perda de espaço das disciplinas de humanidades no currículo a partir da reforma do ensino médio brasileiro, é preciso uma continuidade no debate do tema, principalmente no que diz respeito às razões que justifiquem a importância da educação humanística na formação dos estudantes.

Vale lembrar que, a simples existência dessas disciplinas no currículo, não garantem sua presença na dinâmica formativa dos alunos. Esse processo formativo não pode prescindir das humanidades, sob pena de alijar os futuros brasileiros da possibilidade de se reconhecer como cidadãos capazes de superar a individualidade e se tornar universais, capazes de assumir sua cultura e nela se reconhecer, ao mesmo tempo que também desenvolvem respeito por outras culturas.

A educação humanística, portanto, deve ser mais estimulada e integrada aos conteúdos programáticos das instituições de ensino. Não se trata de um "modismo", mas de uma decisão estratégica para buscar a realização pessoal plena em um mercado de trabalho tão cruel e desumanizado. $O$ ensinar das humanidades é 


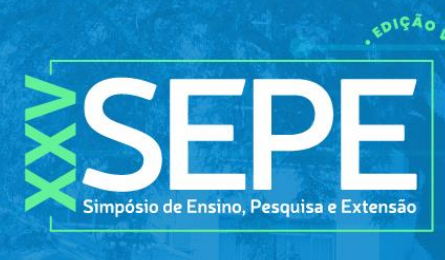

\section{QUFN}

humanizar o ensino, humanizar as pessoas e, em última instância, humanizar a sociedade.

\section{REFERÊNCIAS}

ARANHA, M. L. História da educação. 2 ed. São Paulo: Moderna, 1996.

BURKE P. Uma história social do conhecimento: de Gutenberg a Diderot. Tradução: Plínio Dentzien. Rio de Janeiro: Zahar, 2003, 94 p.

CHERVEL, A.; COMPÈRE, M. M. As humanidades no ensino. Educação e Pesquisa. São Paulo, v. 25, n. 2, p. 149-170, jul/dez, 1999. Disponível em: <https://www.revistas.usp.br/ep/article/view/27826/29598>.Acesso em: 10 jul. 2021.

DIAS, F.C. Humanidades: um tema atual. In: BRASIL. Ensino de humanidades: a modernidade em questão. São Paulo: Cortez, 1991.

GERHARDT, T. E.; SILVEIRA, D. T. (Orgs.) Métodos de pesquisa. Porto Alegre, RS: Editora da UFRGS, 2009. Disponível em:

<http://www.ufrgs.br/cursopgdr/downloadsSerie/derad005.pdf>. Acesso em: 11 jul. 2021.

GIL, A. C. Métodos e técnicas de pesquisa social. 6 ed. São Paulo: Atlas, 2008. Disponível em: <https://ayanrafael.files.wordpress.com/2011/08/gil-a-c-mc3a9todose-tc3a9cnicas-de-pesquisa-social.pdf>. Acesso em: 12. jul. 2021.

KEMP, A.T. O papel das humanidades na educação para a democracia. 2018. 123 f. Tese (Doutorado em Educação nas Ciências) - Universidade Regional do Noroeste do Estado do Rio Grande do Sul, ljuí - RS. Disponível em: $<$ https://bibliodigital.unijui.edu.br:8443/xmlui/handle/123456789/6054> Acesso em: 29 jul. 2021.

NUSSBAUM, M. C. Sem fins lucrativos: por que a democracia precisa das humanidades. 1. ed. São Paulo: Martins Fontes, 2015.

ROUANET, Sérgio Paulo. As razões do iluminismo. São Paulo: Companhia das Letras, 5aㅡ reimpressão, 1998. Disponível em:

<https://www.academia.edu/35109231/ROUANET_S_As_Razoes_do_lluminismo_pd f>. Acesso em: 25 abr. 2021.

SILVA, V. A. As humanidades, os estudos culturais, o ensino da literatura e a política da língua portuguesa. Coimbra, Edições Almedina, 2010. 364p. ISBN: 9789724041957.

WEHLING, A.; WEHLING, M. J. C. de M. Formação do Brasil Colonial. 1 ed. Rio de Janeiro: Ediouro, 1999. 